\title{
Morphological and Molecular Identification of Ixodid Ticks that Infest Ruminants in Erbil province, Kurdistan Region-Iraq
}

\author{
Khalid Jabar Aziz ${ }^{*}$ \\ Department of Animal Resources, College of Agricultural Engineering Sciences, Salahaddin University, Erbil, Kurdistan Region, Iraq
}

Received 17 August 2021; revised 05 September 2021;

accepted 21 September 2021; available online 18 October 2021

doi:10.24271/psr.35

\begin{abstract}
A cross- sectional survey was conducted in Erbil province from April to July 2021 to estimate the prevalence of major Ixodid ticks on ruminants and to identify tick species using morphological and molecular tools. A total of 687 animals (202 cattle, 287 sheep and 198 goats) examined, and 254 (36.9 \%) were infested. About 381 ticks were collected from examined animals. The result identified two genera of six species of the hard ticks based on morphological, molecular investigation. The identified adult ticks morphologically were belonging to the two Ixodid genera, among which three species belonged to the genus Hyalomma (Hyalomma marginatum, Hyalomma anatolicum and H. exacavatum), and three species belonged to the genus Rhipocephalus (Rhipocephalus sanguineu, Rhipocephalus turanicus, and Rhipocephalus B. annulatus). R. annulatus was the dominant tick species infesting cattle with $50 \%$ which was significantly higher at $\mathrm{P}<0.05$ than the other isolated species. Whereas $H$. excavatum and $R$. sanguineus was the prodominant tick species infesting sheep with $29.1 \%$ and $28.3 \%$ respectively. While the infestation rate on goats was $16.7 \%, R$. sanguineus was the most prevailed species infesting goats with $45.4 \%$ at $(\mathrm{P}<0.05)$. R. sanguineus were the predominant tick reported in Erbil governorate with $29.1 \%$ at $(\mathrm{P}<0.05)$., while $H$. excavatum was reported in low percentage in Erbil at $10.2 \%$. DNA samples from sixty ticks were chosen for molecular studies in order to detect tick species using a conventional PCR targeting the 16S rRNA gene. All sequences were subjected to a Basic Local Alignment Search Tool (BLAST) to determine their identities and assess their homologues and similarities to those in the Gen Bank. PCR and the sequencing have confirmed the morphological-based identification, Phylogenetic study revealed that the three Rhipicephalus genotypes revealed from the current study with accession number (MZ663757-MZ663759) were have a highly identical nucleotide sequence $99-100 \%$ with a strain of a Rhipicephalus turanicus, $R$. annulatus and $R$. sanguineus strain sequence (KY583068, MN594491 and MN594492) from China, and Iraq respectively. On the other hand phylogenetic analysis of Hyalomma genotypes from the present work with accession number (MZ663760-MZ663762) were closely related to a Hyalomma anatolicum, $H$. marginatum and Hyalomma exacavatum (MK829042, MG418663, and KP210047) from Egypt, Turkey and India respectively.
\end{abstract}

(C) 2022 Production by the University of Garmian. This is an open access article under the LICENSE

https://creativecommons.org/licenses/by-nc/4.0/

Keywords: Molecular, Morphology, Ixodid tick, Ruminants, Erbil.

\section{Introduction}

Ticks are universal obligatory blood sucking ectoparasite in the class Arachnida, nonpermanent arthropods that infesting both animal and human. They are causing several diseases resulting in economic impact through morbidity or mortality, due to act as a vector of several pathogens including: haemoprotozoan, bacteria and viruses ${ }^{[1,2]}$. Ticks are ectoparasites causing severe economic losses to their hosts through sucking blood and toxic secretions in their saliva leading to anemia, skin damage, reducing weight gain and milk production, inflammation and paralysis ${ }^{[3]}$. Besides,

* Corresponding author

E-mail address: khalid.aziz1@su.edu.krd (Instructor).

Peer-reviewed under the responsibility of the University of Garmian. ticks are responsible for the transmission of various pathogens than any other arthropod vectors groups and they are considered the among the most important vectors cause diseases in animals $[4,5]$.

Ticks have a worldwide distribution, with the highest species diversity in the tropical and subtropical regions ${ }^{[6]}$. There are approximately 900 tick species which nearly $10 \%$ lead to transmit the pathogens in worldwide; the majority of them belong to the two families including: Ixodidae and Argasidae ${ }^{[7,8]}$. Hard ticks of tropical livestock belonging to the genera Rhipicephalus, Boophilus, Hyalomma, and Amblyomma and these are the most ecologically and veterinary significant ${ }^{[9]}$. The sub genus Rhipicephalus (Boophilus) and genus Hyalomma are predominating and have significant impacts on economy in many 
parts of the different countries ${ }^{[10]}$. Tick-borne diseases remain a concern for global animal management, and it is a priority for many states in tropical and subtropical climates due to their economic and veterinary relevance ${ }^{[10]}$.

Tick species identification are essential for managing and treating the tick-borne diseases because tick-borne infections are generally transmitted by variant of tick species ${ }^{[11]}$. Using phenotypic strategies for the determination and differentiation of tick's species are worldwide gold standard, while significantly limited by the possible variation in ticks life cycle stages and also needs to enough training and experience [12, 13]. However, different genetic markers based on sequence analysis of DNA; were employed to identify, classification and phylogenetic studies of arthropods [14]. Nuclear rDNA (18S and 28S) and mitochondrial rDNA (12S and 16S) are of highly important in tick phylogenetic and genetic diversity studies $[8,15]$. Genes particularly, 16S rRNA have been used for molecular recognition and phylogenetic analysis of ticks and is considered well known for barcoding $[16,17]$. Molecular analytical tools have proven valuable and complementary for overcoming this ineffectiveness associated with morphological identification of ticks and have been used to identify and differentiate tick species ${ }^{[18,19]}$.

Several species of Ixodid ticks species were identified morphologically in Erbil Province; such species are H.marginatum, H. anatolicum, H.excavitum, Boophilus annulatus, Boophilus microplus, Rhipicephalus turanicus and R.sanguinueus $[20,21]$. As there are no studies on molecular features of hard tickfs in in Erbil province, the current study was designed to investigate morphological and molecular characters of ruminants Ixodid ticks using PCR and sequencing.

\section{Materials and Methods}

This cross-sectional study was performed from April to July 2021 in Erbil province, Kurdistan Regional, Iraq. Totally 687 ruminants (cattle, sheep and goat) were thorouhgly investigated for tick infestations. Ticks were carefully collected from different part of host body including: eye, ears, neck, udder and external genitalia, per femoral region, legs, inguinal and under tail areas. A total of 381 adult ticks were collected from selected animals varying in age and sex and stored in $70 \%$ ethanol at $4^{\circ} \mathrm{C}$ until morphological and molecular identification of tick's species.

Prior to molecular and phylogenetic analysis the ticks were identified based on morphological classification and taxonomy using stereoscopic microscope (Hertel \& Reuss Stereo microscope STE 6, Kassel, Germany, - Catawiki) according to the identification keys ${ }^{[12,22,23]}$. After appropriate identification, from each species of Ixodid ticks (10) samples of, $R$. sanguineous, $R$. turanicus, $R$ h. (Boophilus) annulatus, $H$. anatolicum, $H$. marginatum and $H$. exacavatum DNA was extracted using PrimePrepTM Genomic DNA Extraction kit (from Tissue) (GeNet Bio, Korea) following manufacture instructions.

In this study, universal primers of $16 \mathrm{~S}$ rRNA gene were used to get fragment of size $460 \mathrm{bp}$ ), and this help to catch different species of hard tick spp., foreword 5'-CCG GTC TGA ACT CAG ATC AAG T-3' and reverse 5'-GCT CAA TGA TTT TTT AAA TTG CTG T-3, ${ }^{[24]}$. The PCR program was followed according to previous study by ${ }^{[24]}$, the reactions were performed in a final volume of $(25 \mu \mathrm{l})$ table (1). The cycling conditions were performed as shown in table (2). Eventually, for 1:40 minutes, $10 \mu \mathrm{l}$ of PCR products were visualized under UV on $1 \%$ agarose gel which run at 85 Volts.

Table 1: PCR components for tick's species subject to conventional PCR assay.

\begin{tabular}{|c|l|c|c|}
\hline \multicolumn{1}{|c|}{ PCR assay } & Chemicals & Concentration & Each reaction \\
\hline \multirow{4}{*}{ Conventional PCR } & PCR Master Mix & $2 \mathrm{X}$ & $12.5 \mu \mathrm{l}$ \\
\cline { 2 - 4 } & $100 \mu \mathrm{M}$ F primer & $20 \mu \mathrm{M}$ & $1 \mu \mathrm{l}$ \\
\cline { 2 - 4 } & $100 \mu \mathrm{M}$ R primer & $20 \mu \mathrm{M}$ & $1 \mu \mathrm{l}$ \\
\cline { 2 - 4 } & DNA Template & $200 \mu \mathrm{M}$ & $2 \mu \mathrm{l}$ \\
\cline { 2 - 4 } & dH2O & ------- & 8.5 \\
\cline { 2 - 4 } & Total & ------ & $25 \mu \mathrm{l}$ \\
\hline
\end{tabular}

Table 2: The thermocycler program for $16 \mathrm{~S}$ rRNA.

\begin{tabular}{|c|c|c|c|c|}
\hline Step & Function of each step & Temperature & & Time \\
\hline 1 & Preheating the lid & $100^{\circ} \mathrm{C}$ & & $5-6 \mathrm{~min}$ \\
\hline 2 & Initial denaturation & $95^{\circ} \mathrm{C}$ & & $5 \mathrm{~min}$ \\
\hline 3 & Denaturation & $95^{\circ} \mathrm{C}$ & & $30 \mathrm{Sec}$ \\
\hline 4 & Annealing & $55^{\circ} \mathrm{C}$ & & $30 \mathrm{Sec}$ \\
\hline 5 & Extension & $72{ }^{\circ} \mathrm{C}$ & & $30 \mathrm{Sec}$ \\
\hline 6 & Cycling & Repeat steps 3-5 & $35 X$ & $35 \mathrm{X}$ \\
\hline 7 & Final extension & $72^{\circ} \mathrm{C}$ & & $5 \mathrm{~min}$ \\
\hline 8 & Storage until removal & $4^{\circ} \mathrm{C}$ & & variable \\
\hline
\end{tabular}

In this study a total of 6 positive PCR products were sent for purification and sequencing into the commercial company (Macrogen Inc. South Korea). Database searches and sequence similarity were performed using the BLAST tool (http://www.ncbi.nlm.nih.gov/BLAST) and comparisons with previous sequences published in GenBank. MEGAX version ${ }^{[25]}$ was used to align sequences. Sequences were aligned together with 16S rRNA gene of tick species sequences, derived from GenBank. 


\section{Statistical Analysis}

Statistical analysis data were interpreted using general linear model (GLM) procedures (SAS, 2002) in completely randomized design (CRD). Duncans New multiple range test ${ }^{[26]}$ was used to seperate the mean.

\section{Results}

A total 381 adult ticks were collected from ruminants (cattle, sheep and goats) from different locations in Erbil province. Based on the morphological data, two genera of Ixodid tick (Rhipicephalus and Hyalomma) were identified; three species belong to the genus Rhipicephalus (Rhipicephalus sanguineus, $R$. turanicus, and $R$. annulatus) and three species belong to the genus Hyalomma (Hyalomma anatolicum, $H$. marginatum and $H$. exacavatum), figure $(1,2)$.

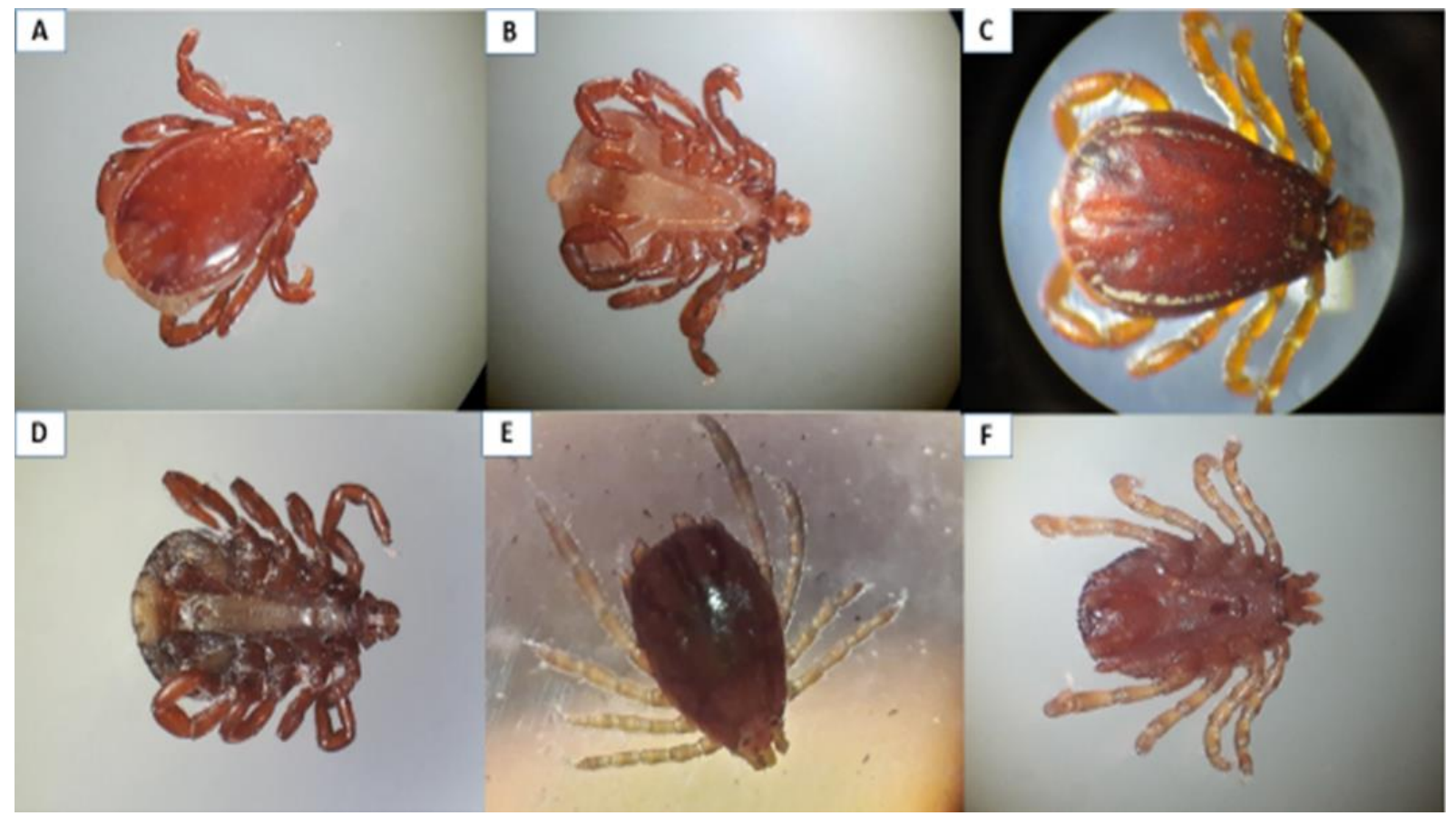

Figure 1: A and B: Rhipicephalus sanguineous dorsal and ventral view male; $\mathbf{C}$ and $\mathbf{D})$ Rhipicephalus turanicus dorsal and ventral view male; $\mathbf{E}$ and

F) Rhipicephalus annulatus dorsal and ventral view male.

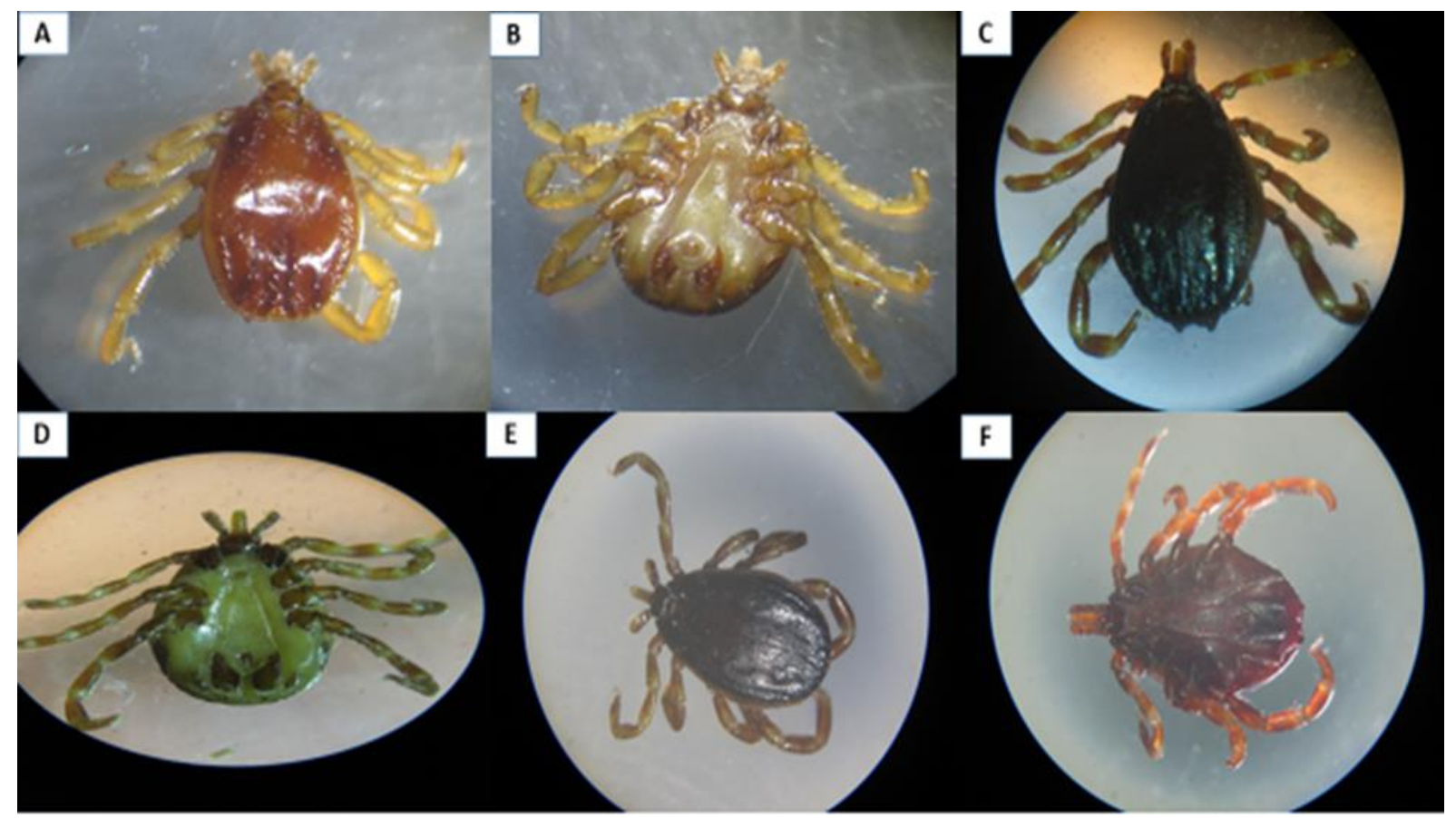

Figure 2: A and B: Hyalomma excavatum dorsal and ventral view male; $\mathbf{C}$ and $\mathbf{D})$ Hyalomma anatolicum dorsal and ventral view male; $\mathbf{E}$ and $\mathbf{F}$ ) Hyalomma marginatum dorsal and ventral view male. 
The data in table (3) shows that the infested rate of Ixodid ticks on cattle is $12 \%$. R. annulatus the dominant tick species infesting cattle at a rate of $50 \%$ which was significantly higher at $\mathrm{P}<0.05$ than the other isolated species. In sheep, the infestation rate with $H$. excavatum and $R$. sanguineus was the same, around $30 \%$.
While the infestation rate on goats was $16.7 \%$ and $R$. sanguineus was the most common species infesting goats with a rate of $45.4 \%$. In Erbil, among all ruminant animals, $R$. sanguineus was the most previaled tick species with $29.1 \%$, while $H$. excavatum was found in lowest rate at $10.2 \%$.

Table 3: The infested rate of ixodide tick species on ruminants.

\begin{tabular}{|c|c|c|c|c|c|c|c|c|}
\hline \multirow{2}{*}{ Tick species } & \multirow{2}{*}{ No. of ticks } & \multirow{2}{*}{$\%$} & \multicolumn{6}{|c|}{ Host } \\
\hline & & & Cattle & $\%$ & Sheep & $\%$ & Goats & $\%$ \\
\hline R. sanguineus & $111 \mathrm{a}$ & 29.1 & $12 \mathrm{bc}$ & 11.8 & $36 a$ & 28.3 & $69 \mathrm{a}$ & 45.4 \\
\hline R. turnicus & $71 \mathrm{~b}$ & 18.6 & $16 \mathrm{~b}$ & 15.7 & $14 \mathrm{bc}$ & 11.0 & $47 \mathrm{~b}$ & 30.9 \\
\hline R. annulatus & $65 \mathrm{~b}$ & 17.1 & $51 \mathrm{a}$ & 50 & $9 \mathrm{c}$ & 7.0 & $6 \mathrm{c}$ & 3.9 \\
\hline H. marginatum & $51 \mathrm{bc}$ & 13.4 & $6 \mathrm{bc}$ & 5.9 & $8 \mathrm{c}$ & 6.3 & $12 \mathrm{c}$ & 7.9 \\
\hline H. anatolicum & $44 \mathrm{c}$ & 11.6 & $14 \mathrm{~b}$ & 13.7 & $23 \mathrm{~b}$ & 18.1 & $13 \mathrm{c}$ & 8.6 \\
\hline H. excavatum & $39 \mathrm{c}$ & 10.2 & $3 \mathrm{c}$ & 2.9 & $37 \mathrm{a}$ & 29.1 & $5 \mathrm{c}$ & 3.3 \\
\hline Total & 381 & 16.7 & 102 & 12.0 & 127 & 16.6 & 152 & 16.7 \\
\hline
\end{tabular}

The results of amplified PCR product using 16S rRNA gene amplification revealed that the DNA amplicon size for the reaction is $460 \mathrm{bp}$ indicating positive samples for target gene figures (3).

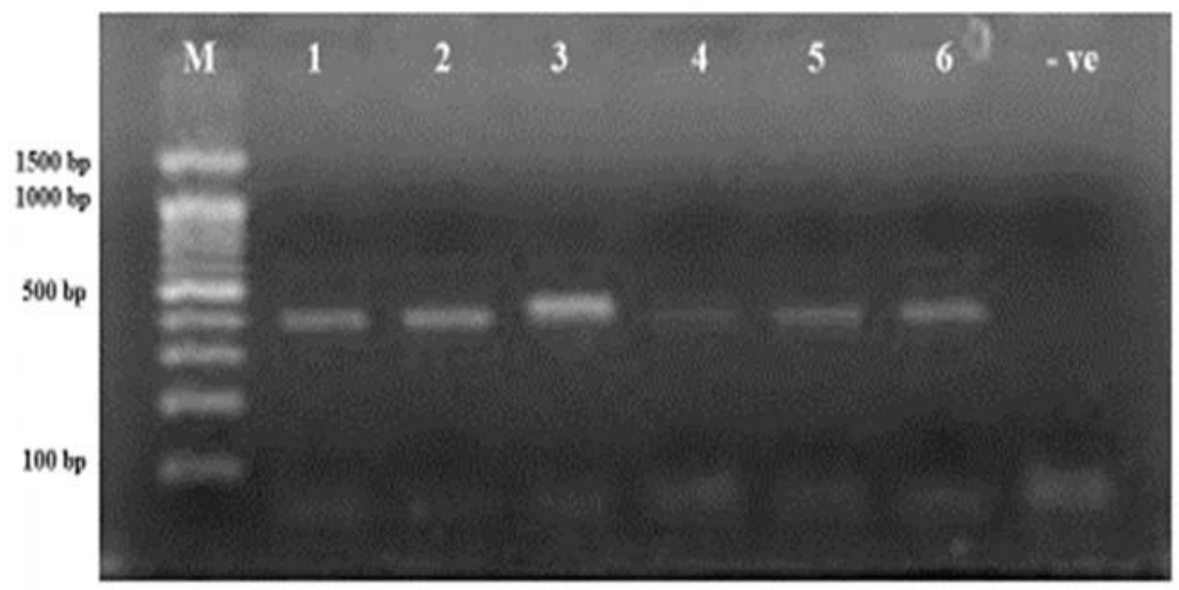

Figure 3: PCR products of Ixodid tick 16S rRNA gene. 100 bp loading DNA ladder and lane 1-2-3-4-5 and 6

The sequences were analyzed, verified and aligned using BioEdit sequence alignment editor. The sequence was submitted to GenBank (accession number from GenBank as following: MZ663757, MZ663758, MZ663759, MZ663760, MZ663761 and MZ663762) table (4). The "BLAST" tool on the National Center for Biotechnology Information (NCBI) website was used to identified and calculat the similarity of the sequence with homologous sequences in GenBank. Form this research, two genera of six species (each genera of three species) of Ixodid ticks were detected by molecular study and sequencing including. Rhipiciphalus and Hyalomma were the identified genera that infect ruminants in Erbil province, Iraq table (4).

Table 4: Genus and species of Ixodid ticks and the GenBank accession numbers.

\begin{tabular}{l|c|c|c|c|c}
\hline Ticks genus & Accession No. & Species & Similarity \% & $\begin{array}{c}\text { Reference } \\
\text { accession No. }\end{array}$ & Country \\
\hline \multirow{3}{*}{ Rhipiciphalus } & MZ663757 & R. sanguineus & 100 & MN594492 & Iraq \\
& MZ663758 & R. turnicus & 99 & KY583068 & China \\
& MZ663759 & R. annulatus & 100 & MN594491 & Iraq \\
\hline \multirow{3}{*}{ Hyalomma } & MZ663760 & H. marginatum & 100 & MG418663 & Turkey \\
& MZ663761 & H. anatolicum & 99 & MK829042 & Egypt \\
& MZ663762 & H. excavatum & 99 & KP210047 & India \\
\hline
\end{tabular}

The Phylogenetic tree of six putative tick species by molecular methods confirmed the existence of species that reported by morphological identification in Erbil in table (4). This shows three major clades representing the H. marginatum (MZ663760) which clustered with $H$. marginatum in turkey with accession number (MG418663), H. analoticum analoticum (MZ663761) 
were closely identical to H. anatolicum from Egypt (MK829042) while Hyalomma excavitum (MZ663762) clustered with Hyalomma excavitum Isolate $\mathrm{Z7}$ in India with accession number (KP210047). R. sanguineus (MZ663757) and $R$. annulatus (MZ663759) clustered with sequences previously detected from
Duhok, Iraq (MN594492), (MN594491) respectively. While $R$. turnicus (MZ663758) sequences were located close to sequences dectected in China (KY583068), and using Amblyomma transversale used as out group as in figure (4).

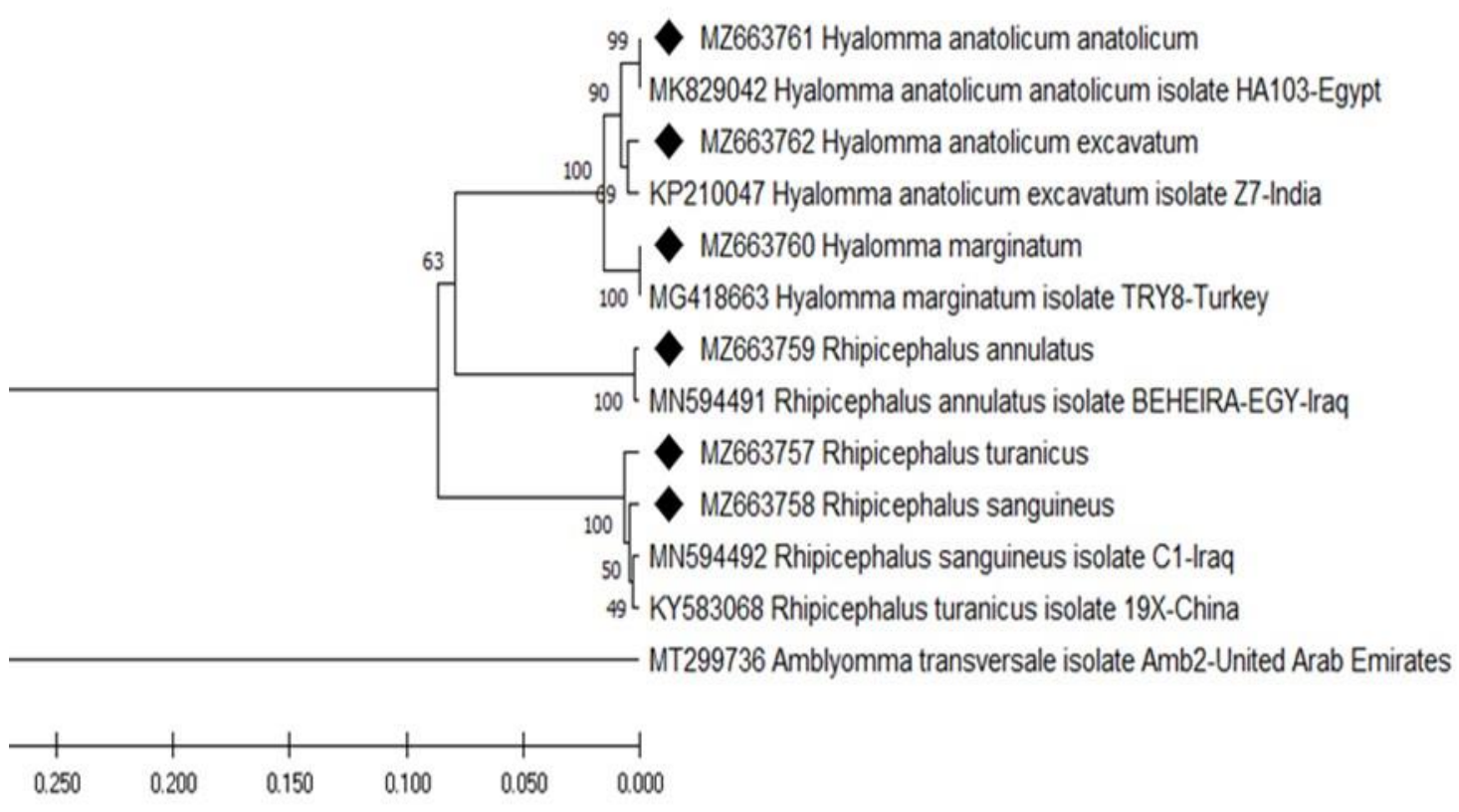

Figure 4: phylogenic tree of tick species.Black diamond labeled sequences derived from the current study; others indicated sequences from references.

\section{Discussions}

The microscopical and molecular examination of Ixodid ticks in ruminant animals (cattle, sheep and goats) identified six species of Ixodid tick belong to two genera of hard ticks, (Rhipocephalus and Hyalomma). Three species of Rhipicephlus ( $R$. sanguineus, $R$. turinus and R. anulatus), and also three species of Hyalomma (H. analoticum, $H$. excavitum and $H$. marginatum) were identified in this study. The distribution of Rhipicephalus spp. appeared to be the predominant tick species in the ruminants. This finding were supported with previous several studies in Kurdistan region, Iraqi by ${ }^{[27,21,17]}$ and in Iran by ${ }^{[28]}$.

Rhipicephalus spp. appeared to be more predominant species in cattle, sheep and goats. These data are in line with the previously resported results of ${ }^{[29]}$ who found that this species are more prevalent species among small ruminants in Duhok governorate. The ticks Rhipicephalus sanguineus, Rhipicephalus turanicus and Hyalomma anatolicum, were found in the center and south of Iraq as well as in the north by ${ }^{[30]}$. In addition, ${ }^{[29]}$ found some species of Ixodid ticks such as Rhipecephalus appendiculatus, $H$. marginatum and $H$. anatolicum. In contrast a study in south of Iraq was disagreeing with these results and reported that Hyalomma spp. were more predominant in south of Iraq ${ }^{[31]}$.

The reason of theses differences in tick infestations could be related to differences in animal rearing circumstances between ecosystems investigated in prior studies, as well as climate change variables in recent years. These finding are inline with what have been suggested in previous studies conducted by ${ }^{[32,33]}$. Phylogenetic analysis and tree allow genetic relationships between closely related species in this country to be resolved with other countries, and it has become a helpful tool in a variety of biological study disciplines ${ }^{[34]}$. The current study's phylogenetic tree was built using 16S rRNA sequences, with deletion, transition, and transvertion of some nucleotide of sequenced samples which impacted onnumber of nucleotide, the 16S rRNA sequence of samples (MZ663757- MZ663762), almost was identical $99-100 \%$ to the sequences of dereference within the GenBank sequences reference with accession number (MG418663, MK829042, KP210047, KY583068, MN594492 and MN594491) was similar to Turkey, Egypt, India, China and Iraq respectively.

\section{Conclusion}

Overall, the findings suggest that Rhipocephalus and Hyalomma are the predominant hard ticks' genera in Erbil based on morphological and molecular studies. This study has deposited 6 ticks sequences information for the 16S rDNA gene in GenBank. Phylogenetically, the identified genotypes were highly identical to that from China, Iraq, Egypt, Turkey and India. Based on the current data, actions need to be taken to control the distribution of the identified tick species to mitigate their economic impacts on the livestock within the region.

\section{Acknowledgements}

The author expresses his deep thanks and gratude to I am very grateful to Dr. Nazhad H. Qader and Dr. Yunis A. Ahmad for their assistance for thefor their help and support during sample collection and using their Molecular Biology Laboratory and I also would like to express my thanks to Dr Khalid S. Ibrahim for 
reading and providing me with comments for a previous version of this paper.

\section{References}

1. Rajput, $\mathrm{ZZ}, \mathrm{Hu}, \mathrm{SH}$, et al., Importance of ticks and their chemical and immunological control in livestock. Journal Zhejiang University Science B, 2006.7 (11): p. 912-921.

2. Aziz, KJ, and AL-Barwary, LTO, Molecular identification of Theileria equi and Babesia caballi from ixodid ticks infesting equids in Erbil province, northern of Iraq. Adv. Anim. Vet. Sci, 2020. 8 (12): p.1286-1293.

3. Wall, RL, and Shearer, D, Veterinary ectoparasites: biology, pathology and control. 2nd ed.John Wiley and Sons, 2008.

4. Giraldo-Ríos $\mathrm{C}$, and Betancur O, Economic and health impact of the ticks in production animals. 2018. https://doi.org/10.5772/intechopen.81167.

5. Huruma, G, et al., Identification of tick species and their prevalence in and around Sebeta town, Ethiopia, Journal Parasitology and Vector Biology, 2015. 7(1): p.1-8.

6. Adham FK, et al., Detection of tick blood parasites in Egypt using PCR assay IBabesia bovis and Babesia bigemina. Parasitol Res, 2009. 105(3): p.721.

7. Stafford, KC, Tick Management Handbook. The Connecticut Agricultural Experiment Station.Bulletin. 2007.10(10): p.79.

8. Guglielmone AA, et al., The Argasidae, Ixodidae and Nuttalliellidae (Acari: Ixodida) of the world: a list of valid species names. Zootaxa, 2010. 2528(6): p.1-28.

9. Frans J. Final Report, Integrated Control of Ticks and Tick-Born Diseases (ICTTD), 2000.

10. Salih, DA, et al., Diagnostic approaches for tick-borne haemoparasitic diseases in livestock. Journal of Veterinary Medicine and Animal Health, 2015.7(2): p.45-56.

11. Takano, A, et al., Tick surveillance for relapsing fever spirochete Borrelia miyamotoi in Hokkaido, Japan, 2014. PLoS One.9(8). pe104532.

12. Estrada-Peña, A, et al., Ticks of domestic animals in the Mediterranean region. University of Zaragoza, Spain, 2014. 131.

13. Rosa, $\mathrm{P}$, et al., Morphological characterization of the ovary and oocytes vitellogenesis of the tick Rhipicephalus sanguineus (Latreille,1806) (Acari: Ixodidae), Experimental Parasitology, 2005. 110(2): p.146-156.

14. Latrofa, MS, et al., Comparative analyses of mitochondrial and nuclear genetic markers for the molecular identification of Rhipicephalus spp. Infection, Genetics and Evolution, 2013. 20: p.422-7.

15. Nava, S, et al., Mitochondrial DNA analysis of Rhipicephalus sanguineus sensu lato (Acari: Ixodidae) in the Southern Cone of South America. Veterinary parasitology, 2012. 190(3-4): p.547-55.

16. Crowder, CD, et al., Extraction of Total Nucleic Acids from Ticks for the Detection of Bacterial and Viral Pathogens. J Med Entomol, 2010. 47(1): p.89-94.

17. Ismael, SS. and Omer, LT, Morphologcal and molecular study of hard ticks' species that infested small ruminants in duhok governorate, kurdistan region, Iraq. Bas. J. Vet. Res, 2020. 19(1): p.88-108.

18. Mohammed, BR, et al., Application of Biotechnology towards Diagnosis and Treatment in Veterinary Medicine in Africa: Potentials and Future Developments. Journal of Biotechnology and Biomaterial, 2016. 6: 245: p.2.

19. Ogo, NI, et al., Morphological and Molecular Characterization of Amblyomma variegatum (Acari:Ixodidae) Ticks from Nigeria. Nigerian Veterinary Journal, 2017. 38(3): p.260-267.

20. Ameen KA, Occurrence of hard tick and its possible role in the transmission of pathogenic agents. University of Mosul, Iraq, 2012.

21. Aziz, KJ, and AL-barwary, LTO, Prevalence rate of ixodid ticks in equids and some nearby farm animals in erbil governorate, north of Iraq, Basrah Journal of Veterinary Research, 2019.18: p.337-359.

22. Walker, ARAR, Ticks of domestic animals in Africa: a guide to identification of species. Bioscience Reports Edinburgh, Edinburgh 2003: P.3-210.

23. Walker, AR, et al., Ticks of Domestic Animals in Africa: A Guide to Identification of Species, 2014. 3-210.
24. Mangold AJ, et al., Mitochondrial $16 S$ rDNA sequences and phylogenetic relationships of species of Rhipicephalus and other tick genera among Metastriata (Acari: Lxodidae). Parasitol Res, 1998. 84: p.478-484. Doi: 10.1007/s004360050433.

25. Kumar, S, et al., MEGA X: molecular evolutionary genetics analysis across computing platforms. Molecular biology and evolution, 2018. 35(6): p.1547.

26. Duncan DB, Multiple range and multiple F tests. Biometrics, 1955.11(1): p.1-42.

27. Omer, LT, et al., Seroprevalence of piroplasmosis with tick distribution in northern Iraq. Iraqi Journal of Veterinary Sciences, 2012. 26(3): p.105-108.

28. Salim abadi, Y, et al., Hard Ticks on Domestic Ruminants and their Seasonal Population Dynamics in Yazd Province, Iran. Iranian J Arthropod-Borne Dis, 2010. 4(1): p.66-71.

29. Omer, LT, et al., A survey of ticks (Acari: Ixodidae) on cattle, sheep and goats in the Dohuk Governorate. Iraq. Parasitol Res, 2007. 101: p.179-181.

30. Kadhum Shubber, HW, et al., Ixodid Ticks Diversity in the Middle and South of Iraq. International Journal of Recent Scientific Research, 2014. 5 (9): p.1518-1523.

31. AL-Fatlawi, M.AA., et al., Morphological and phylogenetic study of Hyalomma anatolicum in Al-Najaf, Iraq. Iraqi Journal of Veterinary Sciences, 2018. 32(2): p. 261266.

32. Mohammad MK, Distribution of ixodid ticks among domestic and wild animals in central Iraq. Bulletin of the Iraq Natural History Museum, 2015. 13(3): p.23-30.

33. Pegram, RG, et al., Seasonal dynamics of the parasitic and non-parasitic stages of cattle ticks in Zambia. Acarology VI/editors, DA Griffiths and CE Bowman,1984.

34. Yang, Z, and Rannala, B, Molecular phylogenetics: principles and practice. Nat. Rev. Genet, 2012. 13(5): p. 303-314. 